\title{
Molybdenum and Tungsten Tricarbonyl Complexes of Isatin with Triphenylphosphine
}

\author{
M. M. H. Khalil ${ }^{1}$ and F. A. Al-Seif ${ }^{2}$ \\ ${ }^{1}$ Department of Chemistry, Faculty of Science, Ain Shams University, Abbassia, Cairo 11566, Egypt \\ ${ }^{2}$ Department of Chemistry, Scientific Departments, Girls' College of Education, P.O. Box 27104X, \\ Riyadh 11417, Saudi Arabia
}

Correspondence should be addressed to M. M. H. Khalil, khalil62@yahoo.com

Received 9 July 2008; Accepted 26 August 2008

Recommended by Wolfgange Linert

Reaction of $\mathrm{M}(\mathrm{CO})_{6} ; \mathrm{M}=\mathrm{Mo}$ or $\mathrm{W}$ with isatin in the presence of triphenylphosphine in THF under reduced pressure gave the tricarbonyl derivatives complexes $\left[\mathrm{M}(\mathrm{CO})_{3}(\mathrm{isatH})\left(\mathrm{PPh}_{3}\right)\right]$. The two complexes were characterized by elemental analysis, infrared, mass and ${ }^{1} \mathrm{H}$ NMR spectroscopy. The spectroscopic studies show that the two complexes exist in fac- and merisomers in solutions through exchange the $\mathrm{CO}$ group and $\mathrm{PPh}_{3}$. The Uv-Vis spectra of the complexes in different solvents were studied.

Copyright (๑) 2008 M. M. H. Khalil and F. A. Al-Seif. This is an open access article distributed under the Creative Commons Attribution License, which permits unrestricted use, distribution, and reproduction in any medium, provided the original work is properly cited.

\section{Introduction}

Isatin (2,3-dihydroindole-2, 3-dione) is a versatile leadmolecule for designing potential bioactiveagents, and its derivatives were reported to possess broad-spectrum antiviral activity $[1,2]$. In the previous reports, the synthesis and characterization of group 6 and 8 complexes of isatin and 5 -methylisatin in absence and presence of bipyridine were investigated $[3,4]$. In this article, we report the synthesis and characterization of molybdenum and tungsten complexes of isatin in the presence of $\mathrm{PPh}_{3}$. The aim of these reactions is the synthesis and study of mixed-ligand complexes, where the metal is surrounded by different donor atoms in the coordination sphere, that is, the oxygen from isatin and phosphorous atom from the triphenylphosphine $\left(\mathrm{PPh}_{3}\right)$. $\mathrm{PPh}_{3}$ is different from the carbonyl group since it is a strong $\sigma$-donor and weak $\pi$-acceptor ligand. Furthermore, the organic phosphenes increase the stability of the transition metal complexes in the low-oxidation state. Taking into account the electronic spectra the combination of a reducing metal and an acceptor ligand generates a metal-to-ligand charge transfer (MLCT) excited state which may appear in absorption and emission $[5,6]$.

\section{Experimental}

2.1. Reagents. $\mathrm{Mo}(\mathrm{CO})_{6}, \mathrm{~W}(\mathrm{CO})_{6}$, isatin, and $\mathrm{PPh}_{3}$ were supplied from (Sigma Aldrich, St. Louis, USA). All the solvents were reagent gradeand purified prior to use.

2.2. Instruments. IR measurements were recorded as $\mathrm{KBr}$ pellets on a Unicam-Mattson 1000 FT-IR spectrometer. Electronic absorption spectra were measured on a Unicam UV2-300 UV-vis spectrophotometer. ${ }^{1} \mathrm{H}-\mathrm{NMR}$ measurements were performed on a Varian-Mercury $300 \mathrm{MHz}$ spectrometer. Samples were dissolved in $\left(\mathrm{CD}_{3}\right)_{2} \mathrm{SO}$ with TMS as internal reference. The complexes were also characterized by elemental analysis (Perkin-Elmer $2400 \mathrm{CHN}$ elemental analyzer) and mass spectroscopy (Finnigan MAT SSQ 7000). Table 1 gives the elemental analyses and mass spectrometry data for the complexes.

$\left[\mathrm{Mo}(\mathrm{CO})_{3}(\right.$ isatH $\left.)\left(\mathrm{PPh}_{3}\right)\right] . \mathrm{Mo}(\mathrm{CO})_{6} \quad(0.20 \mathrm{~g} ; 0.76 \mathrm{mmol})$, isatin (0.06 g; $0.33 \mathrm{mmol}$ ), and $\mathrm{PPh}_{3}(0.09 \mathrm{~g} ; 0.33 \mathrm{mmol})$ were mixed in ca $30 \mathrm{ml}$ tetrahydrofuran. The mixture was degassed and heated to reflux for 4 hours, where the color of 
TABLE 1: Elemental analysis and mass spectrometric data for the molybdenum and tungsten complexes.

\begin{tabular}{lcccccccc}
\hline \multirow{2}{*}{ Complex } & \multicolumn{3}{c}{ Calculated } & \multicolumn{3}{c}{ Found } & \multicolumn{3}{c}{ Mass spectroscopy } \\
& $\% \mathrm{C}$ & $\% \mathrm{H}$ & $\% \mathrm{~N}$ & $\% \mathrm{C}$ & $\% \mathrm{H}$ & $\% \mathrm{~N}$ & $\mathrm{Mwt}$ & $\mathrm{m} / z(P+)$ \\
\hline$\left[\mathrm{Mo}(\mathrm{CO})_{3}(\mathrm{isatH})\left(\mathrm{PPh}_{3}\right)\right]$ & 59.09 & 3.42 & 2.37 & 58.57 & 3.42 & 3.05 & 589.39 & 590 \\
{$\left[\mathrm{~W}(\mathrm{CO})_{3}(\right.$ isatH $\left.)\left(\mathrm{PPh}_{3}\right)\right]$} & 51.42 & 2.98 & 2.06 & 52.05 & 3.06 & 2.39 & 677.29 & 678 \\
\hline
\end{tabular}

TABLE 2: Important IR data for isatin and its complexes.

\begin{tabular}{|c|c|c|c|}
\hline \multirow{2}{*}{ Compound } & \multicolumn{3}{|c|}{ IR data $\left(\mathrm{cm}^{-1}\right)^{\mathrm{a}}$} \\
\hline & $\nu_{(\mathrm{NH})}$ & $\nu_{(\mathrm{C}=\mathrm{C})}+\delta_{\mathrm{CH}}$ & $\nu_{(\mathrm{CO})}$ \\
\hline IsatH & $3191(\mathrm{~s})$ & $\begin{array}{c}\text { 1615(vs), } \\
1461(\mathrm{~s})\end{array}$ & 1748(sh), 1727(vs) \\
\hline$\left[\mathrm{Mo}(\mathrm{CO})_{3}(\right.$ isatH $\left.)\left(\mathrm{PPh}_{3}\right)\right]$ & $3184(w)$ & $\begin{array}{c}1619(\mathrm{~s}) \\
1462(\mathrm{~m}) \\
1435(\mathrm{~m})\end{array}$ & 2013(m),1943(m), 1887(vs), $1725(\mathrm{sh}), 1703(\mathrm{~s})$ \\
\hline$\left[\mathrm{W}(\mathrm{CO})_{3}(\right.$ isatH $\left.)\left(\mathrm{PPh}_{3}\right)\right]$ & $3186(\mathrm{~m})$ & $\begin{array}{l}1619(\mathrm{~m}) \\
1463(\mathrm{~m}) \\
1435(\mathrm{~m})\end{array}$ & 1935(m), 1879(s), 1810(w), 1727(s), 1703(s) \\
\hline
\end{tabular}

${ }^{\mathrm{a}} \mathrm{vs}$, very strong; s, strong; $\mathrm{m}$, medium; $\mathrm{w}$, weak; sh, shoulder.

the solution changed from yellow to dark red. The reaction mixture was cooled and the solvent was removed under vacuum. The obtained solid was washed several times with hot benzene and petroleum ether to give brown crystals with a yield of $55 \%$ based on the metal.

$\left[\mathrm{W}(\mathrm{CO})_{3}(\right.$ isatH $\left.)\left(\mathrm{PPh}_{3}\right)\right]$. A similar procedure was performed as in the case of $\left[\mathrm{Mo}(\mathrm{CO})_{3}(\right.$ isatH $\left.)\left(\mathrm{PPh}_{3}\right)\right]$ but the reaction time was 11 hours (reddish brown powder, yield $48 \%)$.

\section{Results and Discussion}

3.1. IR and NMR Studies. Reactionsof $\mathrm{M}(\mathrm{CO})_{6} ; \mathrm{M}=\mathrm{Mo}$ or $\mathrm{W}$ with isatin in the presence of $\mathrm{PPh}_{3}$ resulted in the formation of $\left[\mathrm{M}(\mathrm{CO})_{3}(\right.$ isat $\left.\mathrm{H})\left(\mathrm{PPh}_{3}\right)\right]$ complexes. The IR spectra of the complexes exhibited characteristic bands of the isatin and $\mathrm{PPh}_{3}$ ligands with the corresponding shifts, Table 2 . In addition, the IR spectra of the complexes showed that the $v_{\mathrm{CO}}$ of isatin ligand exerted $20-45 \mathrm{~cm}^{-1}$ shift to lower frequency suggesting that the coordination of isatin occurred in the range of ketoform in both complexes. On the other hand, the IR spectra of the two complexes exhibited three bands in the metal terminal carbonyl region [7] with shifts toward the low-frequency region, Table 2. Also, the IR spectra exhibited two medium bands at 1099, $1102 \mathrm{~cm}^{-1}$ characteristic $v\left(\mathrm{P}-\mathrm{C}_{\mathrm{Ph}}\right)$ bands indicates the presence of coordinated $\mathrm{PPh}_{3}$ in the complexes, similar to the literature trend [8] and suggesting similarity of the structure of the two complexes. It is generally difficult to determine the stretching frequency $v_{(\mathrm{M}-\mathrm{P})}$ that contains $\mathrm{PPh}_{3}$ because it has many stretching frequencies in the lower-frequency region [9]. However, the IR spectra of the two complexes showed interesting differences. The $v_{\mathrm{CO}}$ of the three terminal

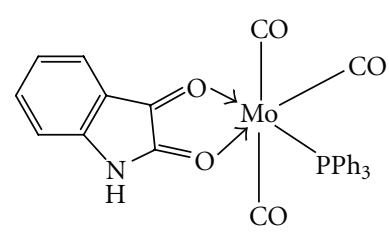

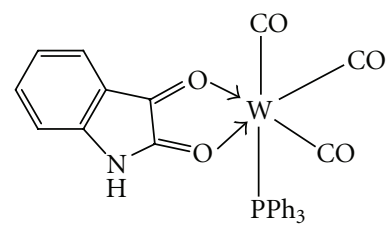

SCHeme 1

carbonyls in the tungsten complex exhibit more shift to lower frequencies than that of the molybdenum complex. This can be contributed to the difference in the metal and arrangements of the ligands in the two complexes. From the positions of the three $\mathrm{CO}$ groups and their intensities, it can be concluded that the complex $\left[\mathrm{Mo}(\mathrm{CO})_{3}(\right.$ isatH $\left.)\left(\mathrm{PPh}_{3}\right)\right]$ couldbe presented in the meridional (mer)-isomer in the solid state and tungsten complex in the facial ( fac)-isomer as shown in Scheme 1.

The ${ }^{1} \mathrm{H}$ NMR spectrum of isatH in deuterated DMSO showed signals at 6.9(d), 7.06(t), 7.5(t), 7.61(d) ppm due to protons of the benzene ring and a signal at $10.98(\mathrm{~s}) \mathrm{ppm}$ due to proton of $\mathrm{NH}$ group [3]. The ${ }^{1} \mathrm{H}$ NMR spectrum of $\mathrm{PPh}_{3}$ showed multiplets in the range of 6.93-7.24 ppm. ${ }^{1} \mathrm{H}$ NMR spectra of the molybdenum complex exhibited two broad singlet signals at 11.02 and $10.86 \mathrm{ppm}$ due to $\mathrm{NH}$ and appearance of a new doublet signal at $9.05 \mathrm{ppm}$ due to one proton in the isatin phenyl ring, in addition to the shifts of isatin and $\mathrm{PPh}_{3}$ as a result of coordination. The ratios of the signals at 11.02 and $10.86 \mathrm{ppm}$ were of (1:3) and 2:1 for molybdenum and tungsten complexes, respectively, suggesting that the complex present in twotautomeric structure. The appearance of the new signal and change in the chemical shift of $\mathrm{NH}$ proton is essentially 


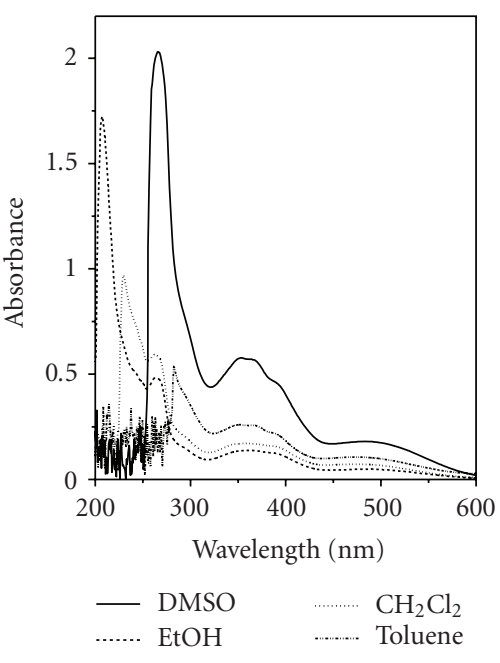

(a)

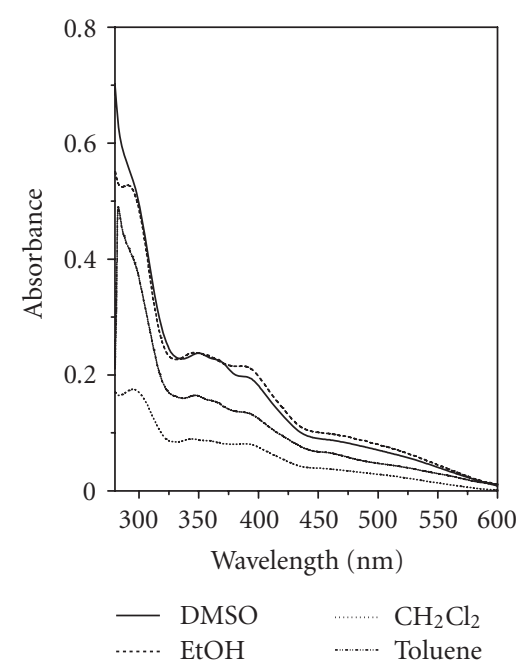

(b)

FIgUre 1: The UV-vis spectra of the (a) $\left[\mathrm{Mo}(\mathrm{CO})_{3}(\mathrm{isatH})\left(\mathrm{PPh}_{3}\right)\right]$, (b) $\left[\mathrm{W}(\mathrm{CO})_{3}(\right.$ isatH $\left.)\left(\mathrm{PPh}_{3}\right)\right]$ complexes in different solvents.

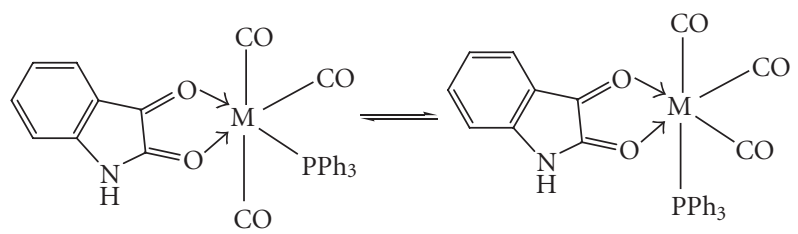

(a)

Scheme 2

related to the presence of the $\mathrm{PPh}_{3}$ and its effect on the chemical shifts of the isatin protons. This shift may be due to mutual anisotropic deshielding between the phenyl group of $\mathrm{PPh}_{3}$ and one proton of the benzene ring of isatin which can affect the signal of NH. This effect is due to magnetic field through space and not through chemical bond by inductive effect [10]. This indicates the possibility of exchange between $\mathrm{CO}$ and $\mathrm{PPh}_{3}$ groups in the solution in the axial position $[11,12]$.

$\mathrm{X}$-ray studies of cis- $\mathrm{RuCl}_{2}(\operatorname{trpy})\left(\mathrm{PPh}_{3}\right)$; where trpy $=$ terpyridine, showed that the $\mathrm{PPh}_{3}$ has two phenyl rings parallel to the trpy while the third phenyl ring nearly perpendicular to the external pyridine of trpy and this lead to low-field shift of the parallel pyridine proton by $1.09 \mathrm{ppm}$. This was not observed for trans- $\mathrm{RuCl}_{2}$ (tepy) $\left(\mathrm{PPh}_{3}\right)$ [13]. From the spectroscopic data, we can concludethat the complexes can exist in mer- and fac-isomers in solution as shown in Scheme 2.

3.2. UV-vis Studies. The absorption spectra of isatin and its complexes were measured in ethanol. Isatin displayed three bands at 249,296 , and $420 \mathrm{~nm}$ due to $\pi-\pi^{*}$ and $n-\pi^{*}$ transitions, Table 3. The solvent effect on the position of the longer wavelength absorption band of isatin
TABLE 3: Absorption data of isatin and its complexes in different solvents.

\begin{tabular}{lcc}
\hline Compound & Solvent & $\lambda(\mathrm{nm})$ \\
\hline \multirow{4}{*}{ Isatin } & DMSO & 334,418 \\
& Ethanol & $249,296,420$ \\
& Toluene & 295,405 \\
& $\mathrm{CH}_{2} \mathrm{CL}_{2}$ & $249,296,415$ \\
\hline & $\mathrm{DMSO}$ & $284,363,389^{\mathrm{a}}, 481$ \\
& Ethanol & $265,353,363,393,491$ \\
{$\left[\mathrm{Mo}(\mathrm{CO})_{3}(\right.$ isatH $\left.)\left(\mathrm{PPh}_{3}\right)\right]$} & Toluene & $282,349,361,387,473$ \\
& $\mathrm{CH}_{2} \mathrm{CL}$ & $263,291,365,473$ \\
\hline & $\mathrm{DMSO}_{2}$ & $248,349,365,358,448$ \\
{$\left[\mathrm{~W}(\mathrm{CO})_{3}(\right.$ isatH $\left.)\left(\mathrm{PPh}_{3}\right)\right]$} & Ethanol & $243,261,290^{\mathrm{a}}, 389,481$ \\
& Toluene & $289,345,357,387,452$ \\
& $\mathrm{CH}_{2} \mathrm{CL}_{2}$ & $263,297,343,379,446$ \\
\hline
\end{tabular}

${ }^{\mathrm{a}}$ shoulder

indicates that the $n \pi^{*}$ transition has some charge transfer (CT) character; the nitrogen atom being the electron donor and the $\beta$-carbonyl group the acceptor. Absorption spectra of the complexes obtained from the reaction of $\mathrm{M}(\mathrm{CO})_{6} ; \mathrm{M}=\mathrm{Cr}$ or Mo with isatin only as a ligand showed a shift or disappearance of the CT band due to complexation through carbonyl group in isatin [3]. The electronic spectra of the complexes showed new bands in the range $360-387 \mathrm{~nm}$ due to complexation and a weak band in the range of $445-490 \mathrm{~nm}$. The longer wavelength band could be attributed to metal-toligand charge transfer transitions. The charge transfer bands for the $\left[\mathrm{Mo}(\mathrm{CO})_{3}(\mathrm{isatH})\left(\mathrm{PPh}_{3}\right)\right]$ were appeared at longer wavelength than the $\left[\mathrm{W}(\mathrm{CO})_{3}(\mathrm{isatH})\left(\mathrm{PPh}_{3}\right)\right]$ Figure 1. This trend was observed for the complexes $\left[\mathrm{Mo}(\mathrm{CO})_{3}(\mathrm{pbiH})\left(\mathrm{PPh}_{3}\right)\right]$ and $\left[\mathrm{W}(\mathrm{CO})_{3}(\mathrm{pbiH})\left(\mathrm{PPh}_{3}\right)\right]$; pbiH $=2-\left(2^{\prime}\right.$-pyridyl $)$ benzimidazole [14] . 


\section{References}

[1] K. J. Kilpin, W. Henderson, and B. K. Nicholson, "Synthesis, characterisation and biological activity of cycloaurated organogold(III) complexes with imidate ligands," Polyhedron, vol. 26, no. 1, pp. 204-213, 2007.

[2] M. C. Rodrìguez-Argüelles, M. B. Ferrari, F. Bisceglie, et al., "Synthesis, characterization and biological activity of $\mathrm{Ni}, \mathrm{Cu}$ and $\mathrm{Zn}$ complexes of isatin hydrazones," Journal of Inorganic Biochemistry, vol. 98, no. 2, pp. 313-321, 2004.

[3] M. M. H. Khalil and F. A. Al-Seif, "Synthesis and characterization of isatin complexes with $\mathrm{M}(\mathrm{CO})_{6}, \mathrm{M}=\mathrm{Cr}$ or Mo," Journal of Coordination Chemistry, vol. 60, no. 11, pp. 1191-1201, 2007.

[4] F. A. Al-Seif and M. M. H. Khalil, "Reactions and charcterization of group 6 and 8 metal carbonyl complexes of 5methylisatin," Journal of Saudi Chemical Society, vol. 11, no. 2, pp. 269-276, 2007.

[5] H. Kunkely and A. Vogler, "Photoluminescence of $\left[2,2^{\prime}\right.$ bis-(diphenylphosphino)-1,1'-binaphthyl]-tricarbonylrhenium(I) chloride originating from an MLCT excited state," Inorganic Chemistry Communications, vol. 2, no. 11, pp. 533-535, 1999.

[6] A. Vogler and H. Kunkely, "Charge transfer excitation of organometallic compounds: spectroscopy and photochemistry," Coordination Chemistry Reviews, vol. 248, no. 3-4, pp. 273-278, 2004.

[7] K. Nakamoto, Infrared and Raman Spectra of Inorganic and Coordination Compounds, John Wiley \& Sons, New York, NY, USA, 5th edition, 1997.

[8] T. S. Lobana, Rekha, R. J. Butcher, A. Castineiras, E. Bermejo, and P. V. Bharatam, "Bonding trends of thiosemicarbazones in mononuclear and dinuclear copper(I) complexes: syntheses, structures, and theoretical aspects," Inorganic Chemistry, vol. 45, no. 4, pp. 1535-1542, 2006.

[9] J. H. S. Green, "The vibrational spectra of ligands and complexes-I. Triethylphosphine and some related compounds," Spectrochimica Acta Part A, vol. 24, no. 2, pp. 137143, 1968.

[10] R. M. Silverstein, G. C. Bassler, and T. C. Morrill, Spectrometric Identification of Organic Compounds, John Wiley \& Sons, New York, NY, USA, 7th edition, 2005.

[11] G. Orellana, A. Kirsch-De Mesmaeker, and N. J. Turro, "Ruthenium-99 NMR spectroscopy of ruthenium(II) polypyridyl complexes," Inorganic Chemistry, vol. 29, no. 4, pp. 882-885, 1990.

[12] G. Predieri, C. Vignali, G. Denti, and S. Serroni, "Characterization of mer and $f a c$ isomers of $\left[\mathrm{Ru}(2,3-\mathrm{dpp})_{3}\right]\left[\mathrm{PF}_{6}\right]_{2}$ (2,3-dpp=2,3-bis(2-pyridyl)pyrazine) by ${ }^{1} \mathrm{H}$ and ${ }^{99} \mathrm{Ru} \mathrm{NMR}$ spectroscopy. Proton assignment by $2 \mathrm{D}$ techniques," Inorganica Chimica Acta, vol. 205, no. 2, pp. 145-148, 1993.

[13] S. B. Billings, M. T. Mock, K. Wiacek, et al., "Comparison of (triphenylphosphine)ruthenium complexes containing the $2,2^{\prime}: 6^{\prime}, 2^{\prime \prime}$-terpyridine (trpy) and 4,4', $4^{\prime \prime}$-tri-t- butyl-2,2' : $6^{\prime}, 2^{\prime \prime}$-terpyridine (trpy*) ligands," Inorganica Chimica Acta, vol. 355, pp. 103-115, 2003.

[14] M. M. H. Khalil, H. A. Mohamed, S. M. El-Medani, and R. M. Ramadan, "New group 6 metal carbonyl derivatives of 2-( $2^{\prime}-$ pyridyl)benzimidazole: synthesis and spectroscopic studies," Spectrochimica Acta Part A, vol. 59, no. 6, pp. 1341-1347, 2003. 


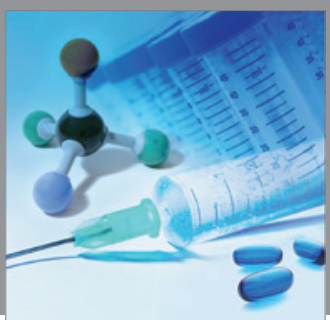

International Journal of

Medicinal Chemistry

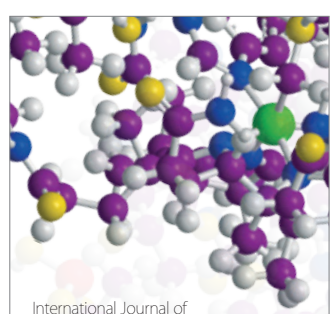

Carbohydrate Chemistry

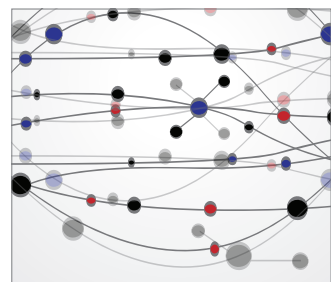

The Scientific World Journal
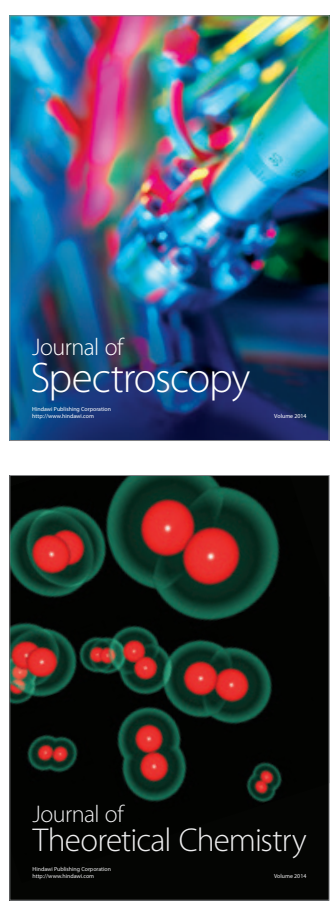
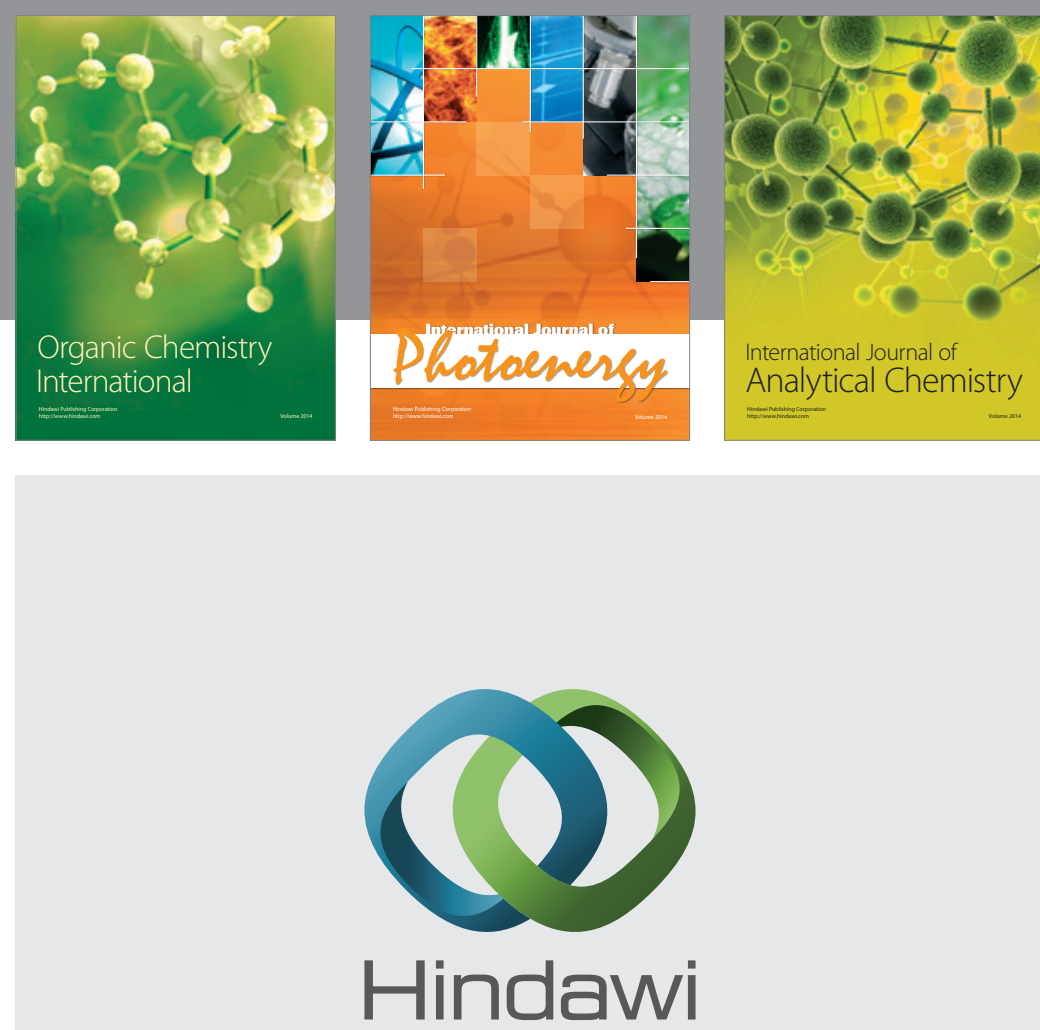

Submit your manuscripts at

http://www.hindawi.com
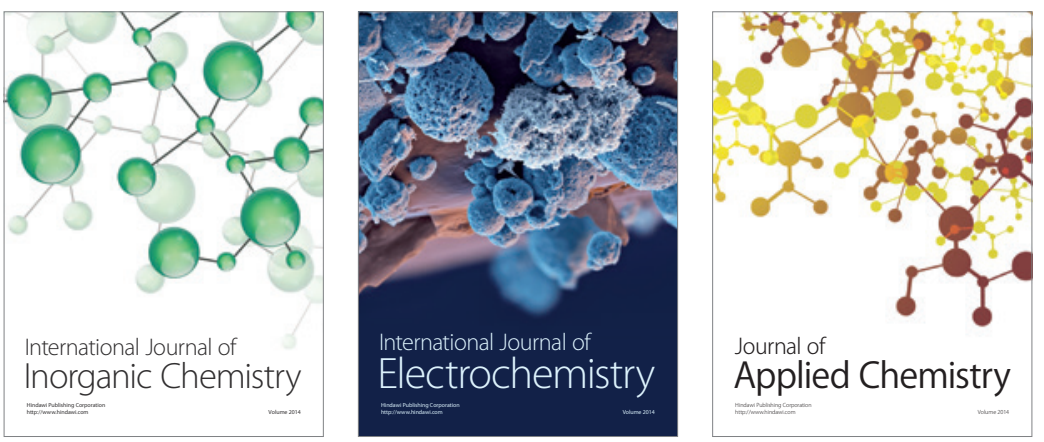

Journal of

Applied Chemistry
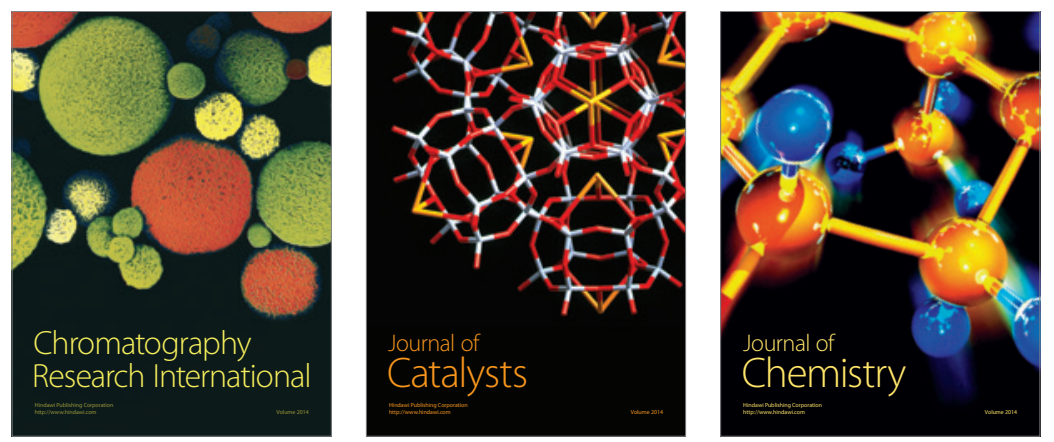
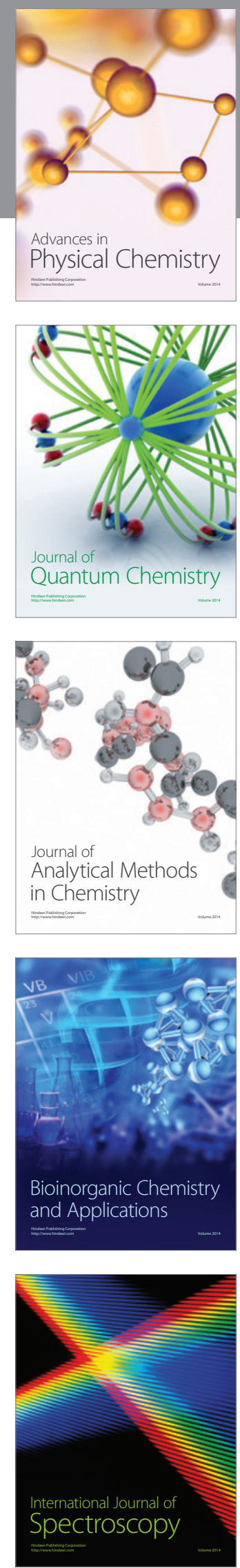